University of Nebraska - Lincoln

DigitalCommons@University of Nebraska - Lincoln

Papers in Communication Studies

Communication Studies, Department of

2014

Communicatively Managing Religious Identity Difference in Parent-Child Relationships: The Role of Accommodative and Nonaccommodative Communication

\author{
Colleen Warner Colaner \\ University of Missouri, colanerc@missouri.edu \\ Jordan Soliz \\ University of Nebraska-Lincoln, jsoliz2@unl.edu \\ Leslie R. Nelson \\ University of Missouri,1rnm9c@mail.missouri.edu
}

Follow this and additional works at: http://digitalcommons.unl.edu/commstudiespapers

Part of the Critical and Cultural Studies Commons, Gender, Race, Sexuality, and Ethnicity in Communication Commons, and the Other Communication Commons

Colaner, Colleen Warner; Soliz, Jordan; and Nelson, Leslie R., "Communicatively Managing Religious Identity Difference in ParentChild Relationships: The Role of Accommodative and Nonaccommodative Communication" (2014). Papers in Communication Studies. 164.

http://digitalcommons.unl.edu/commstudiespapers/164

This Article is brought to you for free and open access by the Communication Studies, Department of at DigitalCommons@University of Nebraska Lincoln. It has been accepted for inclusion in Papers in Communication Studies by an authorized administrator of DigitalCommons@University of Nebraska - Lincoln. 


\title{
Communicatively Managing Religious Identity Difference in Parent-Child Relationships: The Role of Accommodative and Nonaccommodative Communication
}

\author{
Colleen Warner Colaner, ${ }^{1}$ Jordan Soliz, ${ }^{2}$ and Leslie R. Nelson ${ }^{1}$ \\ 1. Department of Communication, University of Missouri \\ 2. Department of Communication Studies, University of Nebraska \\ Corresponding author - Colleen Warner Colaner, Department of Communication, University of Missouri, 212 \\ Switzler, Columbia, MO 65211, email colanerc@missouri.edu
}

\begin{abstract}
Guided by Communication Accommodation Theory, we examine the communicative management of religious difference in parent-child relationships. Using survey data from emerging adults $(N=409)$, we found that religious difference is associated with decreases in relational satisfaction and shared family identity. Further, parents' religious communication has the potential to promote relational well-being. Accommodative communication (religious-specific supportive communication and respecting divergent values) was associated with increases in relational satisfaction and shared family identity. Two forms of nonaccommodative communication (inappropriate self-disclosure and emphasizing divergent values) were associated with decreases with relational satisfaction and shared family identity; giving unwanted advice was associated with decreases in relational satisfaction but not shared family identity. Giving unwanted advice moderated the relationship between religious difference and relational satisfaction. Differences were also discovered between families with interfaith and intrafaith parental dyads. Findings suggest theoretical and methodological contributions to family communication, religious, and intergroup research.
\end{abstract}

Family and religious scholars have long noted the strong role the family plays in religious life (Gunnoe, Hetherington, \& Reiss, 1999; Regnerus, Smith, \& Smith, 2004). Religion is 
often a family affair, as many religions emphasize family values, thus encouraging cohesiveness among family members (Edgell, 2005). Parents are arguably the strongest influence on childhood and adolescent religious identity (Flor \& Knapp, 2001), and families in which all members share the same religious beliefs tend to have high levels of relational quality (Regnerus, 2003). Given the centrality of religion to many families, it is not surprising that family researchers are increasingly turning their attention to the intersection of religion and family (e.g., Braithwaite et al., 2012; Hughes \& Dickson, 2006).

Recent research, however, is demonstrating the prevalence of differences between parents and their adult children concerning religion. More than a quarter of adults have left the religion in which they were raised (Pew Forum on Religion and Public Life, 2008) as individuals are becoming more likely to switch religions during their years of early adulthood (Lawton \& Bures, 2001). The religious identities of emerging adults are becoming increasingly individualized as they report little similarity between childhood socialization and current religious practice (Arnett \& Jensen, 2002). As such, religious identity-defined as the degree to which an individual is committed to a religious group and views that religious group as important to defining the self-is a part of one's self-concept that is increasingly distinct from a family's collective identity. In fact, the number of popular press books on interfaith families (e.g., There's an Easter Egg on Your Seder Plate: Surviving Your Child's Interfaith Marriage, Reuben, 2007) and the numerous online forums focusing on children's different religious beliefs indicate that this is a significant issue for many of today's families.

Based on research done on interfaith couples, we know that religious difference is associated with relational distress in families. Yet, there are limited empirical investigations of parent-child relationships in the context of interfaith families. Interfaith couples have higher rates of conflict (Chinitz \& Brown, 2001), are more likely to divorce (Hughes \& Dickson, 2006), and have lower levels of relational satisfaction (Parsons, Nalbone, Killmer, \& Wetchler, 2007). Such associations suggest that parent-child relationships may also experience decreased relational well-being when the parent and child do not agree on religion. It is likely that the manner in which family members talk about religious difference is more important than the degree to which they actually differ (Hughes \& Dickson, 2005). Communication accommodation theory (CAT) provides a useful lens for understanding the degree to which individuals manage differences through their communication as accommodative communication offers the opportunity for individuals to transcend differences by fostering a connection of inclusion and mutual respect.

Given the strong associations between religious identity and family life, the rising number of families experiencing differences in religious identification, and the importance of communication for managing religious difference, we utilize CAT to explore religious difference in the parent-child relationship. We specifically aim to investigate (a) the degree to which differences in religious identity between parent(s) and their adult children are associated with decreased relational well-being, (b) the role that communication about religion plays in minimizing (or amplifying) this potential effect of religious difference, and (c) the degree to which structural components of the family relate to the relationship between religious difference and relational well-being by comparing individuals that come from interfaith parental dyads (i.e., different religions) versus those from intrafaith (i.e., same 
religion) parental dyads. In this, our goal is to identify modifiable family communication processes that will benefit individuals and professionals (e.g., family therapists) working with families as they attempt to minimize distressful consequences of religious difference in the family.

\section{Religious Difference and Relational Well-being}

Intergroup theorizing provides a foundation to investigate how differences in religious identification may relate to relationship quality. An intergroup perspective on human relations highlights the role social identities play in our interactions, demonstrating that much of our communication is influenced by collective identities (e.g., race/ethnicity, gender, nationality, age), which in turn shape or reflect our self-concept, perceptions of others, and the manner of our communication (Giles, Reid, \& Harwood, 2009). Intergroup research has traditionally been applied to understanding relations in nonintimate interactions, often representing macro-level social issues (e.g., interethnic conflict). Recently, scholars have used this perspective to shed light on communication in personal relationships based on the idea that even our most intimate relationships (e.g., family) are infused with intergroup dynamics (Harwood, 2006).

We typically perceive family as a collective "ingroup" characterized by shared values, customs, and manners of communication. Yet, individual family members may have distinct social identities (Soliz \& Rittenour, 2012), which can often create corresponding "outgroups" in the family system (e.g., age in grandparent-grandchild relationships, race/ethnicity in multiracial/ethnic families, sexual identity in families with gay or lesbian family members). Harwood (2006) offers an agenda for intergroup family research stating that, "a social identity approach will be crucial in understanding when and how these individuals categorize as ingroup (family) versus outgroup (different races, faiths, ages, etc.) members and the influence of such categorization on family communication" (p. 87). In the current study, we focus on one social identity-religious identity-due to documented increases in religious differences in the family (Arnett \& Jensen, 2002; Farrell, 2011; Lawton \& Bures, 2001). We specifically examine the degree to which differences in religious identification in the family work to create outgroups in which one member perceives another family member as belonging to a differing social group (i.e., religion).

Scholars have begun to examine the implications of divergent religious identities in the context of interfaith couples. Hughes and Dickson (2005) demonstrated that religious differences can be a source of relational difficulty in marriages. We continue this reasoning by assessing the degree to which children perceive differences in religious identity, regardless of the actual affiliations of the parent and child. Hughes and Dickson's findings, paired with findings from other religious scholars, give support for the degree to which differences in religious identification likely strain the parent-child relationship. Religious parents devote great energy toward socializing their children into a particular religion (Flor \& Knapp, 2001; Gunnoe et al., 1999; Regnerus et al., 2004). If an individual rejects his or her parents' religion, such a change in religious identity could be viewed as a disloyalty to the family. Depending on the degree of difference between parent and child religious identity, relational well-being may decline as family members experience conflict between family 
and religious ideals. Therefore, the first goal of the current project is to explore the relational implications of religious difference in parent-child relationships.

In assessing the role of religious difference as it relates to relational well-being, we focus upon two constructs in the current study. First, relational satisfaction, or the degree to which an individual feels happy and fulfilled with his or her place in the family, is integral to positive family relationships (Olson, 2000). Additionally, family researchers interested in the ways in which family members manage difference have turned to the common ingroup identity model (Gaertner \& Dovidio, 2000) as it highlights the ways in which families reconcile divergent social identities (such as religious differences) with a common family identity. Therefore, our second indicator of relational well-being is shared family identity, referring to the degree to which individuals perceive a common ingroup with another family member. Although an aspect of relational well-being, shared family identity is unique from relational satisfaction with its emphasis on a collective identity and, thus, minimization of perceptions of group-based difference. In sum, evidence suggests that religious difference will be associated with relational well-being. Confirming this theorizing on identity difference and relationships, we expect to see decreases in relationship well-being in parent-child relationships that have salient interfaith (i.e., intergroup) distinctions.

H1: Parent-child religious difference is negatively related to relational well-being.

\section{Communicative Management of Religious Difference}

Communication is at the heart of the management of difference in interactions, and researchers have relied on Communication Accommodation Theory (CAT) as a guiding theory of the communication behaviors related to intergroup contact in various contexts (Gallois, Ogay, \& Giles, 2005). At its core, CAT underscores the degree to which communication can be a catalyst for interpersonal affiliation or, conversely, a means of amplifying or maintaining distinctiveness and social distance. Continuing this line of inquiry, the second goal of the present study is to assess the degree to which parental communication about religion allows family members to manage religious difference.

\section{Accommodative Communication in Parent-Child Relationships}

Accommodative behaviors are those communication behaviors that acknowledge and respect the conversational partner's perceived interpersonal and divergent group characteristics through linguistic, paralinguistic, discursive, and nonlinguistic adaptation (Gallois et al., 2005; Harwood, 2000). There are numerous ways to categorize accommodative behaviors such as the degree to which one manages discourse by selecting appropriate topics of conversation, controls the conversation through body language and interruptions, and adapts the selection and delivery of verbal communication to increase interpretability (Harwood, Soliz, \& Lin, 2006); the interpretation of what is considered to be accommodative is dependent upon the context and skill of the communicators. In the present study, we target two accommodation behaviors demonstrated to be important in other family research taking an intergroup approach (e.g., Harwood, 2000; Rittenour \& Soliz, 2009; Soliz 
\& Harwood, 2006; Soliz, Thorson, \& Rittenour, 2009) and relevant to religious difference: religious-specific supportive communication and respecting divergent values.

In general, supportive communication conveys care and concern (Burleson \& MacGeorge, 2002), incorporating elements of immediacy, receptiveness, and equality (Weber \& Patterson, 1996). Such support can potentially ameliorate negative effects of intergroup distinctions by personalizing interactions (Soliz, Thorson, \& Rittenour, 2009). Religious-specific supportive communication incorporates the immediacy and responsiveness elements of supportive communication, but specifically focuses on religious beliefs. Since messages about religion that express affection, involvement, trust, and receptivity tend to relate to positive relational outcomes (Mikkelson \& Hesse, 2009), religious-specific supportive communication likely plays an important role in conversations about religious difference as it communicatively demonstrates acceptance of an individual as a valued family member despite divergent religious identities.

Feeling as though one's social identity is respected plays an important role in individual well-being and self-esteem (De Cremer \& Tyler, 2005). People demonstrate respect for divergent values by adapting their communication so that they do not offend, belittle, or disregard another's beliefs. Softening statements that may be interpreted as threatening, avoiding direct judgments, and expressing tolerance for another's values can convey respect for another's beliefs. Due to the highly personal nature of religious beliefs and the important relationship between respect of one's social identity and individual well-being, affirmation of one's core values is likely important in promoting relationship well-being. Given the positive associations between accommodation and relational well-being in previous research, we predict that accommodation specific to religious communication has similar associations:

$\mathrm{H}$ 2: Accommodative communication behaviors are positively associated with relational well-being.

\section{Nonaccommodative Communication in Parent-Child Relationships}

Whereas accommodative communication attempts to meet the conversational partner's needs, nonaccommodative behaviors fail, intentionally or unwittingly, to incorporate the partner's identity and communicative needs into the interaction (Gallois et al., 2005; Harwood, 2000). Three behaviors specific to religious talk within families are highlighted in the present study based on previous intergroup research (e.g., Harwood, 2000; Rittenour \& Soliz, 2009; Soliz \& Harwood, 2006; Soliz, Thorson, \& Rittenour, 2009) and relevance to the current context: inappropriate self-disclosure, emphasizing divergent values, and giving unwanted advice.

Inappropriate self-disclosure occurs when individuals offer excessive and unwanted information about their religious experience. In other work using a CAT framework, inappropriate disclosures in a general (i.e., nonreligious) capacity were detrimental to the relationship because such communication fails to acknowledge the implications of one's communication on the relational partner's conversational needs and preferences (Harwood, 2000). Specific to religious families, children with parents who talked excessively about religion expressed frustration with their relationship (Colaner, 2008). Disclosures about religious 
experiences that are disproportionate to the expectations of the conversational partner will likely be related to decreased relational well-being, especially in the context of religious difference.

Emphasizing divergent values is considered nonaccommodative communication behavior because it accentuates differences of salient social identities (Rittenour \& Soliz, 2009). An individual can draw attention to differing religious identities indirectly by selecting topics that are known to be controversial or directly by openly criticizing another's belief. Judgments of religious commitments during conversation highlight differences in religious identities. Argumentative and aggressive communication within religious conversations tends to make individuals feel uncomfortable (Mikkelson \& Hesse, 2009), and communication that targets differences in religious identities may serve to be a source of hurt and frustration, thus relating to decreased relational well-being.

Finally, giving unwanted advice has emerged in intergroup research as a negative predictor of relational well-being. For instance, in the context of mother-in-law/daughter-in-law relationships, participants identified the giving of unwanted advice as a frustration in their relationships (Rittenour \& Soliz, 2009). In applying these behaviors to religious difference, situations in which an individual gives advice based on one's own religious principles assumes that the relational other identifies with such principles. Religiously based advice may be viewed as patronizing or controlling, and recipients may interpret such advice as a denunciation of their own religious beliefs, thus experiencing a decrease in relational well-being. Given the negative outcomes generally associated with nonaccommodative communication, we predict that nonaccommodation specific to religious communication has similar associations:

H3: Nonaccommodative communicative behaviors are negatively associated with relational well-being.

Taking this body of research as a whole, the nature of communication has the potential to influence the relationship between religious difference and relationship well-being. In addition to having direct associations, these behaviors may interact with levels of religious difference in associating with relational well-being. Accommodative communication offers an opportunity for family members to transcend differences in religious identities by emphasizing commonality and acceptance and, thus, may minimize the negative relationship between religious difference and relational satisfaction and shared family identity. Conversely, nonaccommodative communication may accentuate differences in religious identification and exacerbate the tensions manifest in the parent-child relationship.

H4: The negative relationship between parent-child religious difference and relationship well-being is moderated by accommodative communication behaviors such that the negative association decreases with increased accommodative behaviors. 
H5: The negative relationship between parent-child religious difference and relationship well-being is moderated by nonaccommodative communication behaviors such that the negative association increases with increased nonaccommodative behaviors.

\section{Interfaith Parental Dyads and Parent-Child Religious Difference}

Interfaith relationships have been steadily increasing over the last several decades. Researchers estimate that approximately $50 \%$ of marriages occur across faith lines (Pew Forum on Religion and Public Life, 2008). Although interfaith couples are at greater risk for relational dissatisfaction and dissolution, marital communication variables are more predictive of relational well-being than religious difference (Hughes \& Dickson, 2006). This finding suggests that the way in which relational partners in interfaith unions communicate about religion is important for relational stability. It is possible that families with an interfaith parental dyad have experience in communicatively managing religious difference and, thus, interfaith marriages may provide parents with a model for addressing religious differences with their child - an experience that is not present in intrafaith parental dyads (i.e., families in which parents have the same religion).

To investigate both process and structure as a possible source of variation, the third goal of the present study is to understand differences in families from interfaith versus intrafaith parental dyads in the experience and management of religious difference in the parentchild relationship. For instance, shared family identity is not tied as strongly to a common religious identification in families with an interfaith religious dyad as religious difference is already a structural characteristic of the family. As such, individuals with interfaith parents likely experience less relational strain associated with religious difference. We pose the following:

RQ: Does religious difference and (non)accommodation operate differently for families with an interfaith parental dyad than for individuals with an intrafaith parental dyad?

\section{Method}

\section{Participants and Procedures}

The sample consisted of 409 individuals enrolled in introductory undergraduate courses at a large Midwest university. ${ }^{1}$ To qualify for the study, participants needed to indicate that they (a) were 19 years of age or older based upon the age of consent in the state in which the data was collected, (b) spent at least a year or more of their upbringing in a religious home, and (c) perceive that there are currently differences between their religious identity and the religious identity of at least one of their parent(s).

There were more male ( $n=220,53.79 \%)$ than female $(n=136,33.25 \%)$ participants in the current study (approximately $13 \%$ of the sample did not provide data to identify their sex). ${ }^{2}$ Participants provided information on their religious identification. Participants were given examples to illustrate the nature of the question (e.g., "such as Catholic, Protestant, Jewish, 
Mormon, Muslim, Buddhist, Atheist, Agnostic, etc."), then were asked to write in their religious identification. This method allowed individuals to self-identify their religion without constraint. The majority of the sample indicated that they identified as Protestant/Christian ( $n=148,36.19 \%)$ or Catholic $(n=125,30.56 \%)$. The remainder of the sample classified themselves as Agnostic $(n=60,14.67 \%)$, Atheist $(n=43,10.51 \%)$, Jewish $(n=5,1.22 \%)$, Deist $(n=3,0.73 \%)$, Muslim $(n=3,0.73 \%)$, Seventh-Day Adventist $(n=2$, $0.49 \%)$, Animist $(n=1,0.24 \%)$, Buddhist $(n=1,0.24 \%)$, Hindu $(n=1,0.24 \%)$, or Mormon $(n=1,0.24 \%)$. A small portion of the sample indicated that they were undecided about their religious beliefs $(n=4,0.98 \%)$. The remainder of the sample did not provide information on their religious beliefs ( $n=12,2.93 \%$ ) yet still indicated religious difference.

Our sample was divided into two subsamples based on whether the participants came from families with an interfaith or intrafaith parental dyad. We utilize Parsons et al.'s (2007) definition of interfaith, referring to relationships in which individuals are in a relationship with a person of a different faith (e.g., Jewish/Christian) as opposed to conceptualizations of interfaith that consider differences in religious salience (e.g., involvement) and other aspects of religious orientation. Assessing religious identity this way is more consistent with our social identity framework because it allows for the identification of religious groups within couples. In contrast, intrafaith parental dyads occur when individuals are in a relationship with someone who identifies with the same religion (e.g., Christianity). Based on these definitions, the majority of individuals came from families with intrafaith parental dyads in which both parents were members of the same religious group $(n=234,57.2 \%)$. However, a large portion of the sample $(n=160,39.1 \%)$ came from families in which the parents were members of different religious groups.

\section{Measures}

The online questionnaire consisted of measures concerning religious difference, relational characteristics, and (non)accommodative communication. Unless otherwise noted, possible responses for all items range from (1) strongly disagree to (5) strongly agree with high scores representing high levels of the construct.

\section{Religious Difference}

Because religious difference is subjective in nature, we developed five items to assess perceived degree of religious difference between the participant and his/her parent(s) based on general theorizing about interpersonal solidarity and shared beliefs (e.g., I feel like my religious ideas are very similar to my parent(s)' religious ideas; My religious beliefs are not at all like my parent(s)' beliefs; I basically believe the same things that my parent(s) do; I really identify with my parent(s)' religion; I do not consider myself to share any religious beliefs with my parent(s).). Cronbach's alpha for this set of items was $.89(M=2.84, S D=0.98)$.

\section{Relational Well-being}

Two measures assessed relational well-being. First, relational satisfaction was assessed using the Marital Opinion Questionnaire (Huston, McHale, \& Crouter, 1986), modified to reflect the parent-child relationship. This measure uses 10 semantic differential items (ranging 
from 1 to 7 ) that assess specific aspects of relationship satisfaction (e.g., miserable/enjoyable; rewarding/disappointing). Additionally, one Likert-type item measured global satisfaction on a scale of very dissatisfied (1) to very satisfied (7). The 11 items were averaged to create a composite score of relational satisfaction $(M=5.69, S D=1.03)$. Cronbach's alpha for this set of items was .94. Second, shared family identity was assessed using Soliz and Harwood's (2006) six-item measure indicating the extent to which individuals identify as members of the same family (e.g., I feel as if we are members of separate groups; I feel as if we are members of one family). Cronbach's alpha for this set of items was .84 ( $M=4.47$, $S D=0.62)$.

\section{(Non)accommodative Communication}

Communication behaviors were measured by assessing participants' perceptions of his/her parent(s)' accommodation. Twenty-nine items assessed the two accommodative (religiousspecific supportive communication and respecting divergent values) and three nonaccomodative behaviors (emphasizing divergent values, giving unwanted advice, and inappropriate disclosure). Items were drawn from existing measures assessing (non)accommodation communication (Harwood, 2000; Rittenour \& Soliz, 2009; Soliz \& Harwood, 2006; Soliz, Thorson, \& Rittenour, 2009) and adapted to address religious difference. After an itemlevel analysis for each dimension, we subjected all the items to a confirmatory factor analysis (CFA) using Mplus (Muthén \& Muthén, 2010) to assess discriminant validity of these measures. The initial CFA resulted in poor model fit: $\chi^{2}(545)=1988.44, \chi^{2} / d f=3.65, p<.001$, $C F I=.81$, RMSEA $=.08$ (95\% CI: .079, .084).

Based on these results, items were removed if they threatened divergent and convergent validity (e.g., dual loading). The final CFA of the remaining items (and corresponding factors) demonstrated acceptable model fit: $\chi^{2}(142)=297.11, \chi^{2} / d f=2.10, p<.001, C F I=.96$, RMSEA $=.05$ (95\% CI: .04, .06). Finally, to assess validity, we examined correlations between these (non)accommodation scales and the Communication-Based Emotional Support Scale (Weber \& Patterson, 1996; alpha = .90). Given the empirically supported relationship between supportive communication and relational well-being (e.g., Rittenour \& Soliz, 2009), we would expect positive associations with accommodative behaviors and negative associations with nonaccommodative behaviors. Validity was supported, as the correlations are all significant and in the expected direction. ${ }^{3}$ All items used for these five scales are included in Table 1. Reliabilities for the measures as estimated by Cronbach's alpha were acceptable (religious-specific supportive communication: $\alpha=.83, M=3.40, S D$ $=.85$; respecting divergent values: $\alpha=.76, M=3.61, S D=0.71$; inappropriate self-disclosure: $\alpha=.86, M=2.39, S D=0.82$; emphasizing divergent values: $\alpha=.76, M=2.36, S D=0.86$; giving unwanted advice: $\alpha=.83, M=2.91, S D=0.91$ ). 


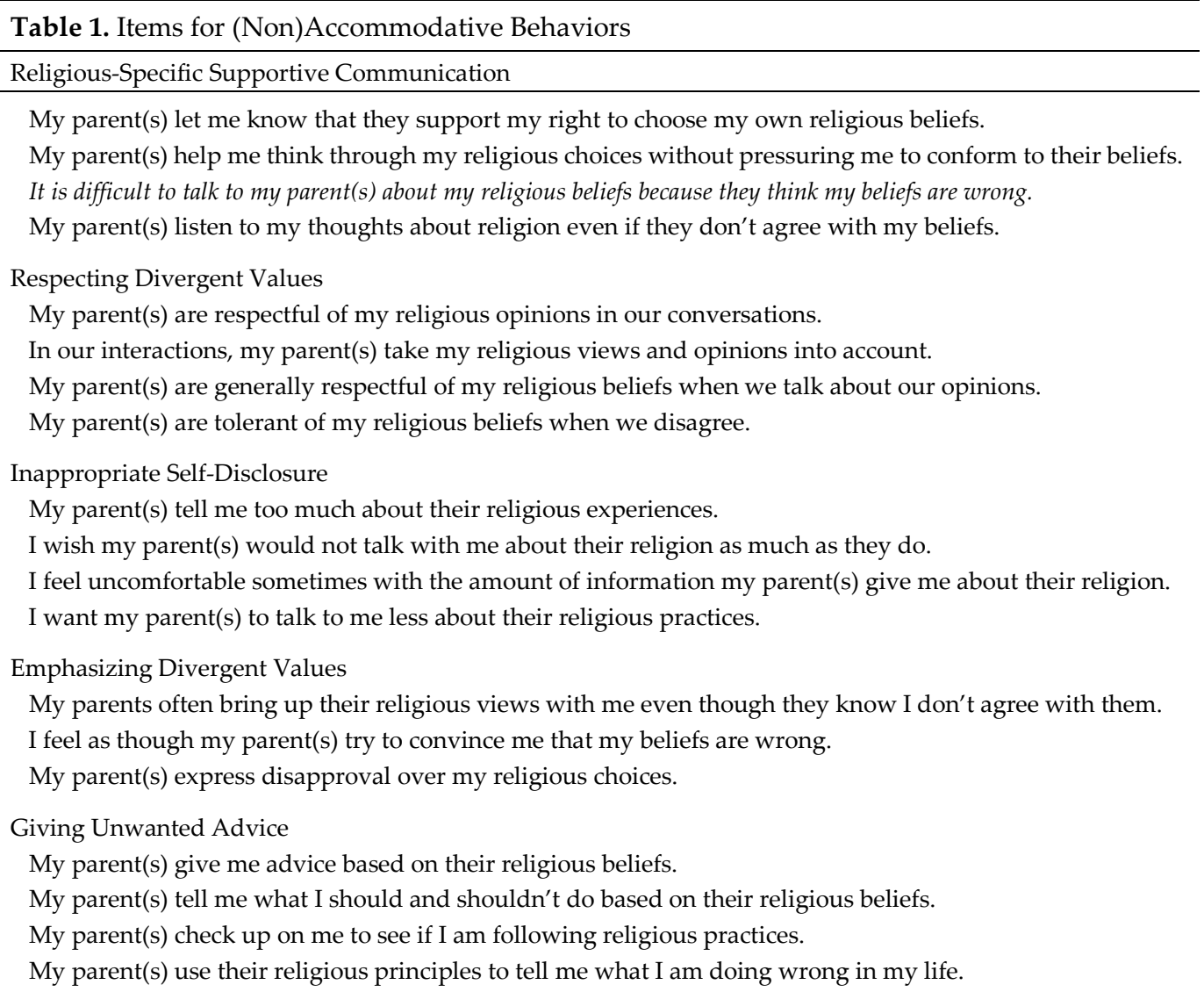

Note: The item in italics is reverse-coded.

\section{Results}

Based on the zero-order correlations, $\mathrm{H} 1$ was supported in that perceptions of religious difference were negatively associated with relational satisfaction $(r=-.28, p<.05)$ and shared family identity $(r=-.27, p<.05)$. $\mathrm{H} 2$ was supported in that religious-specific supportive communication was positively associated with relational satisfaction $(r=.47, p<.05)$ and shared family identity $(r=.30, p<.05)$; similarly respecting divergent values was also positively associated with relational satisfaction $(r=.52, p<.05)$ and shared family identity $(r=.33, p<.05)$. H3 was partially supported as emphasizing divergent values was negatively associated with relational satisfaction $(r=-.43, p<.05)$ and shared family identity $(r=-.30, p<.05)$; similarly, inappropriate self-disclosure about religious beliefs and ideals was negatively associated with relational satisfaction $(r=-.32, p<.05)$ and shared family identity $(r=-.28, p<.05)$. Whereas unwanted advice concerning religion was negatively associated with relational satisfaction $(r=-.20, p<.05)$, there was not a significant relationship with shared family identity $(r=-.08, p=.11)$.

The next pair of hypotheses examined the degree to which (non)accommodative communication moderated the relationship between religious difference and relational well- 
being. To test $\mathrm{H} 4$ and $\mathrm{H} 5$, we assessed interaction effects for each (non)accommodation behavior based on Hayes' (2012) recommendations for testing moderation in regression analysis. Using Hayes' PROCESS macro in SPSS, religious difference and the moderating variable were entered in an ordinary least-squares regression model with one of the two variables representing relational wellbeing. PROCESS mean-centers the variables and creates an interaction term that is entered into the regression equation with the two meancentered predictor variables. When a significant interaction emerged, we used two functions of PROCESS to probe the interaction. First, we examined regression slopes $(b)$ at three levels of the moderating variable (one standard deviation above the mean, the mean, and one standard deviation below the mean). In doing so, we examined how the relationship between religious difference and the outcome variable (relational satisfaction and/or shared family identity) varies based on the level of the moderator. Second, we utilized the Johnson-Neyman (J-N) technique to identify specific regions within the range of the moderator variable in which the effect of the independent variable upon the dependent variable is significant (Hayes \& Matthes, 2009). The J-N technique provides additional rigor in probing interactions due to the specific and nonarbitrary nature of the decomposition method.

In all cases, the overall regression models were significant. Given the nature of the hypotheses, we report only the interaction effects and any subsequent decomposition of the interaction. Standardized betas for the interaction terms for these moderations can be found in Table 2. Four regression models were conducted to assess H4, which predicted that accommodative behaviors (religious-specific supportive communication and respecting divergent values) would moderate the relationship between religious difference and relational well-being (relationship satisfaction and shared family identity). H4 was not supported as none of the four moderations were significant.

Table 2. Beta Coefficients for Interactions Terms in Moderation Analysis

\begin{tabular}{|c|c|c|c|c|c|c|}
\hline & \multicolumn{2}{|c|}{ Overall } & \multicolumn{2}{|c|}{$\begin{array}{c}\text { Interfaith } \\
\text { Parental Dyad }\end{array}$} & \multicolumn{2}{|c|}{$\begin{array}{c}\text { Intrafaith } \\
\text { Parental Dyad }\end{array}$} \\
\hline & RS & SFI & RS & SFI & RS & SFI \\
\hline $\begin{array}{l}\text { Religious-Specific } \\
\text { Supportive Communication }\end{array}$ & .03 & .00 & .10 & $.14 *$ & -.01 & -.03 \\
\hline Respecting Divergent Values & .07 & .05 & $.22 *$ & $.29 * *$ & -.03 & -.05 \\
\hline Inappropriate Self-Disclosure & .04 & .05 & -.00 & -.01 & .09 & $.09 *$ \\
\hline Emphasizing Divergent Values & -.01 & .03 & -.12 & -.11 & .07 & $.09 *$ \\
\hline Giving Unwanted Advice & $-.10 *$ & .01 & -.05 & .03 & -.13 & -.02 \\
\hline
\end{tabular}

Note: RS = Relational Satisfaction, SFI = Shared Family Identity

$* p<.05, * * p<.01$

Six regression models were conducted to assess $\mathrm{H} 5$, which predicted that nonaccommodative behaviors (emphasizing divergent values, giving unwanted advice, and inappropriate self-disclosure) would moderate the relationship between religious difference and relational well-being (relationship satisfaction and shared family identity). There was slight support for $\mathrm{H} 5$ as one of the six interactions was significant. Specifically, giving un- 
wanted advice emerged as moderator between relational difference and relational satisfaction. Results of the interaction decomposition are presented in Table 3, demonstrating that the negative relationship between religious difference and relational satisfaction was strongest with higher frequencies of unwanted advice about religion.

Table 3. Regression Slopes (b) for Religious Difference at Various Levels of a Moderator

\begin{tabular}{|c|c|c|c|c|c|c|}
\hline \multicolumn{7}{|c|}{ Moderator-Outcome } \\
\hline \multirow[b]{2}{*}{ Level of Moderator } & \multirow{2}{*}{$\begin{array}{l}\text { Overall } \\
\text { GUA-RS }\end{array}$} & \multicolumn{3}{|c|}{ Interfaith Parental Dyad } & \multicolumn{2}{|c|}{ Intrafaith Parental Dyac } \\
\hline & & RSSC-SFI & RDV-RS & RDV-SFI & ISD-SFI & EDV-SFI \\
\hline$+1 s d$ & $-0.47 * *$ & -0.10 & -0.04 & -0.02 & 0.02 & 0.06 \\
\hline$M$ & $-0.38 * *$ & $-0.19 * *$ & $-0.17 * *$ & $-0.19 * *$ & -0.06 & -0.03 \\
\hline$-1 s d$ & $-0.28 * *$ & $-0.29 * *$ & $-0.30 * *$ & $-0.37 * *$ & $-0.14 * *$ & $-0.11 *$ \\
\hline
\end{tabular}

Note: $\mathrm{EDV}=$ Emphasizing Divergent Values, ISD = Inappropriate Self-Disclosure, GUA = Giving Unwanted Advice, RDV = Respecting Divergent Values, RS = Relational Satisfaction, RSSC = Religious Specific Supportive Communication, SFI $=$ Shared Family Identity

$* p<.05, * * p<.01$

Regions of significance generated by the J-N technique show one point of transition. When giving unwanted advice is 1.53 or above, the coefficient for religious difference on relational satisfaction is significantly negative, meaning that for all but $9.29 \%(n=38)$ of the sample, giving unwanted advice tends to increase the negative impact of religious difference on relational satisfaction. Those who reported very low levels of parents giving unwanted advice, however, did not experience a negative relationship between religious difference and relational satisfaction.

Our research questions focused on differences between families with interfaith versus intrafaith parental dyads. Fisher's $Z$ tests were calculated to compare correlations between the five (non)accommodation variables and the two relational well-being measures for each sub-sample. The only significant difference was found for the emphasizing divergent values-relational satisfaction relationship [intrafaith: $r(232)=-.49$, interfaith $(158)=-.31, Z$ $=2.07$ ], suggesting that emphasizing difference through discussion of values does more to reduce relational satisfaction in families with parents who share the same religious identity. Next, we compared the means for the five (non)accommodative behaviors for both groups.

As depicted in Table 4, there was a significant difference for three of these five behaviors: religious-specific supportive communication, respecting divergent values, and emphasizing divergent values. Participants from families with interfaith parental dyads reported higher frequencies of accommodative behaviors whereas participants from families with intrafaith dyads reported higher frequencies of parent(s) emphasizing divergent values. Likewise, there was a marginally significant difference for giving unwanted advice, suggesting that this communication behavior is less frequent in interfaith parental dyads. 
Table 4. Mean Comparisons of (Non)accommodative Communication in Interfaith and Intrafaith Parental Dyads

\begin{tabular}{|c|c|c|c|}
\hline \multirow[b]{2}{*}{ Communication Variable } & \multicolumn{2}{|c|}{ Mean (SD) } & \multirow[b]{2}{*}{ Results of $t$-Tests } \\
\hline & Interfaith & Intrafaith & \\
\hline Religious-Specific Supportive Communication & $3.63(0.68)$ & $3.24(0.92)$ & $t(392)=4.59, p<.001$ \\
\hline Respecting Divergent Values & $3.71(0.60)$ & $3.53(0.78)$ & $t(390)=2.33, p<.05$ \\
\hline Inappropriate Self-Disclosure & $2.42(0.81)$ & $2.38(0.84)$ & $t(390)=0.41, p=.68$ \\
\hline Emphasizing Divergent Values & $2.22(0.78)$ & $2.49(0.91)$ & $t(390)=2.91, p<.01$ \\
\hline Giving Unwanted Advice & $2.81(0.95)$ & $2.98(0.95)$ & $t(390)=1.83, p=.07$ \\
\hline
\end{tabular}

To address differences in moderation, separate analyses were conducted with subsamples of interfaith and intrafaith parental dyads using the same procedures as described above. All the interaction terms are reported in Table 2 . Here, we describe only the models that differ from the analysis conducted with the entire sample. New interaction effects emerged when examining participants with interfaith parental dyads $(n=160)$ : religiousspecific supportive communication in relation to shared family identity and respecting divergent values in relation to both relational satisfaction and shared family identity. As such, three out of the four interactions for accommodative communication were significant for the interfaith subsample; no new interactions emerged for nonaccommodative communication models. Table 3 displays the results at various levels of the moderation.

These results suggest that, for individuals with an interfaith parental dyad, the negative relationship between shared family identity and parent-child religious difference is weakest when parent(s) use communication that supports the child's beliefs and respects their child's divergent religious views. Regions of significance produced by the J-N technique identified one point of transition for each of the moderators. When religious-specific supportive communication was 4.07 or below and respecting divergent values was 4.01 or below, there was a negative relationship between religious difference and shared family identity; however, the negative relationship between religious difference and shared family identity was not significant for individuals reporting the highest $20 \%$ of religious-specific supportive communication $(n=32)$ and the highest $11.88 \%$ of respecting divergent values $(n=19)$. When respecting divergent values was 3.86 or below, there was a significant negative relationship between religious difference and relationship satisfaction. Religious difference, however, was not significantly related to decreases in relationship satisfaction for those reporting the highest $48.75 \%$ of respecting divergent values $(n=78)$.

For participants with an intrafaith parental dyad $(n=234)$, accommodative behaviors did not moderate the relationship between religious differences and relational well-being. Two out of six moderations for nonaccommodation emerged in relation to shared family identity: inappropriate self-disclosure and emphasizing divergent values. Table 3 presents results at various levels of the moderation and demonstrates that, for individuals with an intrafaith parental dyad, the negative relationship between religious difference and shared family identity is lessened when parent(s) emphasize their own religious views. Likewise, disclosure from the parent(s) about religious experiences (even if uncomfortable or undesired) minimizes the negative relationship between religious difference and perceptions of a common family identity in these families. 
Regions of significance produced by the J-N technique identified one point of transition for both of the moderators. When inappropriate self-disclosure is 2.20 or below and when emphasizing divergent values is 1.93 or below, there is a negative relationship between religious difference and shared family identity. For the majority of the sample (inappropriate self-disclosure: $n=131,55.98 \%$; emphasizing divergent values: $n=180,76.92 \%$ ), however, religious difference was not significantly related to shared family identity.

\section{Discussion}

The purpose of this study was to explore the communicative management of religious difference in parent and adult-child relationships. Situated in an intergroup perspective (Giles et al., 2009) and utilizing Communication Accommodation Theory (CAT), we tested associations between religious difference, (non)accommodative communication, and relational well-being. Overall, the current study - in extending CAT into a new context-offers three main contributions to family scholarship in the areas of (a) parent-child communication, (b) intergroup communication, (c) and religious communication.

\section{Communicatively Managing Religious Differences in the Parent-Child Relationship}

Results indicate that religious difference between parents and adult children may compromise relationship well-being. Specifically, that relational satisfaction and shared family identity was diminished for individuals experiencing religious difference in both interfaith and intrafaith families. Thus, regardless of whether children come into families where interfaith dimensions are already present, religious difference with a parent (or parents) is associated with diminished relational solidarity and satisfaction. Despite the potential relational difficulties posed by religious differences, our findings illustrate the manner in which family members can communicatively manage religious differences in ways that promote relationship well-being.

Our findings join previous studies in demonstrating the positive nature of accommodative communication in family relationships (e.g., Harwood, 2000; Rittenour \& Soliz, 2009; Soliz, 2007; Soliz et al., 2009). Accommodative communication processes within the family provide an opportunity to transcend religious differences. Despite the fact that all the participants in the current study perceived there to be a difference between their own and their parent's religious beliefs, religious-specific supportive communication and respecting divergent values were related to both relationship satisfaction and shared family identity. Interestingly, interfaith parental dyads were more likely to use these forms of accommodative communication, which served to lessen the impact that religious difference had on relational outcomes.

Such increased use of parental accommodation likely stems from the history of religious difference in the family, suggesting that parents with different faiths may have more experience handling religious difference. These communicative practices are likely embedded in the overall family communication environment. Individuals with a same faith partner, however, likely devoted considerable energy toward socializing their child into the family's religion (Regnerus, 2003), and, hence, may display more hesitancy in accepting their child's differing religious belief. Regardless of religious family structure, findings 
demonstrate that communication that conveys respect, acceptance, and tolerance of religious views may serve to bolster a common family identity between parents and adult children despite religiously diverse affiliations.

In contrast to the positive correlates of accommodative communication, findings give insight into the degree to which nonaccommodative communication may be a source of relational harm in families experiencing religious difference. Inappropriate disclosure, in which parents emphasize their own religious views without regard to their child's divergent beliefs, highlights differences in religious identification. Similarly, emphasizing divergent values, occurring when parents attempt to exert control over their child's religious views, not only highlights differences but also makes a value judgment of the perceived superiority of one set of religious beliefs.

Both of these forms of nonaccommodative communication related to decreases in both relational satisfaction and shared family identity in both intrafaith and interfaith families. Yet, intrafaith families displayed a unique pattern in the present study. Emphasizing divergent values was particularly negative for intrafaith families' relational well-being. However, emphasizing divergent values and inappropriate self-disclosure interacted with religious difference. Specifically, the negative relationship between shared family identity and religious difference was not present when parents displayed high levels of nonaccommodation. Given the centrality of religion to families with same faith parents (Edgell, 2005), communication focusing on religion, even when such communication does not align with the child's divergent social identity, may reinforce core beliefs of the family. Therefore, whereas this aspect of nonaccommodation may impede relationship satisfaction between the parent and child, it may serve to underscore the principle values central to the family's identity.

In light of the significant relationships between religious differences, relational wellbeing, and (non)accommodation, a number of nonsignificant relationships were present in the analysis. Given the infancy of this research, such findings are useful in developing our understanding of religious talk in parent-child relationships. Overall, there were more significant relationships for shared family identity than relational satisfaction in the moderation analysis. As such, the manner and content of communication may be more important for fostering connection among family members than producing positive feelings about the state of one's relationship. Even more, relational satisfaction may be an idiosyncratic construct, meaning that what individuals perceive to be satisfying varies across relationships. Instead of assessing relational satisfaction, perhaps relational standards might be more telling of relational well-being in parent-child relationships (Caughlin, 2003).

Relational satisfaction presumes that individuals desire rich and meaningful connections with their parent. Perhaps such an assumption is not consistent with this sample. Emerging adults tend to experience tension in readjusting roles, privacy, and autonomy with their parents (Arnett, 2004). These life-transition issues, confounded by the religious differences reported by the participants, may create a scenario in which distance from the parent is actually preferable. As such, an adult child may be satisfied with their level of disconnection with their parent because they prefer to reinforce their position of autonomy. Relational standards, however, may indicate participants' idea of how parents and children should behave and the degree to which their relationship holds up to that standard. 
Whereas relational satisfaction was largely unsupported in the moderation analysis, a unique pattern emerged with shared family identity. Interactions between religious difference and (non)accommodation did not predict shared family identity for the overall sample, but different moderations were significant in subsamples of interfaith and intrafaith parental dyads. For families with interfaith parental dyads, nonaccommodation did not moderate the relationship between religious difference and shared family identity; for families with an intrafaith parental dyad, accommodation was not a significant moderator. Examining this distinct pattern underscores importance of assessing both process and structure. In the present study, the degree to which (non)accommodation moderates the relationship between religious difference and shared family identity would have been underplayed had we not examined these relationships in subsamples based on structural elements of the family. Future research should continue to expound upon the ways that the religious structure of the family as well as the ways in which parents communicate about religion has implications for managing religious differences.

\section{Intergroup Dynamics in Family Relationships}

The present study joins a growing line of research investigating intergroup dynamics of family interaction (Harwood, 2006; Soliz \& Rittenour, 2012). This research demonstrates the manner in which communication can assist families in emphasizing common ingroup membership and sustaining positive family relationships in light of social group differences. In focusing on religious differences, we extend the research on intergroup dynamics in family relationships into a new context. Results reinforce the notion that religious difference may introduce an intergroup element within family relationships.

As individuals perceived there to be a difference between their religious identity and that of their parents, they tended to have lower levels of shared family identity. Given that perceptions of shared family identity are based on relationships in which intergroup distinctions are diminished in favor of an inclusive family identity, individuals in the present study seem to be experiencing a clash between their personal religious identification and their identification as a member of the same family as their parents. Given that religion is among the most important factors determining individual beliefs, attitudes, and behaviors in areas such as politics, culture, family life (Banerjee, 2008), divergent religious identities within the same family are likely infused with other divergent social identities or value orientations.

\section{Assessing Religious-Specific Communication}

In addition to contributions in the areas of communicative management of religious difference and intergroup/family scholarship, the present study makes a third contribution in the area of assessment of religious communication. Rather than focusing on general assessments of family communication, this study takes a nuanced approach to intergroup contact in targeting specific communication behaviors related to one dimension of social identityreligious identity. In doing so, we have introduced the applicability of CAT to assess religious communication. The dimensions of (non)accommodative communication utilized in the present study have value for future researchers interested in assessing religious-specific communication behaviors as well as family practitioners interested in providing family 
members with perceptions of religious-based communication when facing difficulty stemming from religious difference.

\section{Limitations and Future Research}

The contributions of the current project must be considered in light of the study's limitations. First, the current study focused on perceptions of religious difference, yet there are numerous ways to assess religious beliefs. Examination of levels of religiosity and/or the salience of the religious identity of family members will offer additional insight into the degree to which religious difference may relate to perceptions of communication, ingroup status, and relational well-being.

Similarly, measuring the religious orientation of parents, referring to the meaning individuals place on religion, may give greater insight into the interfaith dynamics within parental dyads. Similarly, interfaith parental dyads were assessed in the present study based on differences in macro-level religious groupings (e.g., Christian/Jewish) rather than interdenominational memberships within similar faiths. Differences at the denominational level, however, could prove to be important when assessing (non)accommodative communication and religious differences. Future research should assess multiple indicators of parental religion such as religiosity, religious salience, orientation, and religious practice in addition to denominational affiliation to further explore the degree to which religious differences within the family relate to communication and relational variables.

Second, we choose to focus in the current project on specific (non)accommodative behaviors. Although each of these explained significant variance in family relational wellbeing, there are undoubtedly other communication constructs important to families experiencing religious difference. Future work should continue to identify additional forms of (non)accommodative communication relevant to the management of parent-child religious difference.

Finally, the generalizability of the sample is limited to individuals in the emerging adult stage of life. Although research has demonstrated that this group experiences increased turbulence related to religious identification (Barry \& Nelson, 2005), the degree to which such religious difference relates to relational well-being in other age groups is unknown. Third, the direction of the relationship between religious difference and relational wellbeing cannot be determined in the present study due to the cross-sectional nature of the data. Instead of religious difference resulting in decreased satisfaction, it is possible that lower quality relationships contribute to less similarity in religious identification. Longitudinal research is necessary to determine the direction of this relationship. Additional research in more representative samples over time will give greater insight into the experience of religious differences in families.

\section{Conclusion}

Although it may be difficult for parents and children to navigate the relational difficulties associated with divergence on social identities and value orientations, the family environment does not have to be characterized or perceived as overly problematic or turbulent. 
Our communication is an ever-present force that can be used to affirm difference, illuminate our common goals, highlight our positive aspects of relationships, and, in the end, create a shared sense of inclusion while allowing for unique identities and experiences.

Acknowledgments - The authors would like to thank the editor and the anonymous reviewers for their helpful comments on earlier drafts of the manuscript.

\section{Notes}

1. Participants were part of a larger subject pool in which individuals could select studies to participate in based on qualifications. Participants learned about the study through a centralized information system for all research activities. Participants are not required to complete research studies.

2. Due to issues with the online survey, some demographic information was not collected (e.g., race/ethnicity, age). Based on demographics of our sampling frame, requirements for participation, and similar studies from this sampling frame, we can assume that vast majority of participants are White/Caucasian and they are between the ages of 19 and 24.

3. Correlation between communication-based social support and (non)accommodation communication are as follows: Religious-Specific Supportive Communication, $r=.48, p<.001$; Respecting Divergent Values, $r=.54, p<.001$; Inappropriate Self-Disclosures, $r=-.31, p<.001$; Emphasizing Divergent Values, $r=-.36, p<.001$; Giving Unwanted Advice, $r=-.14, p<.01$.

\section{References}

Arnett, J. J. (2004). Emerging adulthood: The winding road from the late teens through the twenties. New York, NY: Oxford University Press.

Arnett, J. J., \& Jensen, L. A. (2002). A congregation of one: Individualized religious beliefs among emerging adults. Journal of Adolescent Research, 17, 451-467. doi:10.1177/0743558402175002

Banerjee, N. (2008). Americans change faiths at rising rate, report finds. Retrieved from http://www .nytimes.com/2008/02/25/us/25cnd-religion.html.

Barry, C. M. N., \& Nelson, L. J. (2005). The role of religion in the transition to adulthood for young emerging adults. Journal of Youth and Adolescence, 34, 245-255. doi:10.1007/s10964-005-4308-1

Braithwaite, D. O., Breshears, D., Stafford, L., Davis, K. L., Mongeau, P. A., Keeley, M., \& Colaner, C. W. (2012). Religion, spirituality, and interpersonal communication. Paper presented at the National Communication Association, Orlando, FL.

Burleson, B. R., \& MacGeorge, E. L. (2002). Supportive communication. In M. L. Knapp \& J. A. Daly (Eds.), Handbook of interpersonal communication (pp. 374-424). Thousand Oaks, CA: Sage.

Caughlin, J. P. (2003). Family communication standards: What counts as excellent family communication and how are such standards associated with family satisfaction? Human Communication Research, 29, 5-40. doi:10.1111/j.1468-2958.2003.tb00830.x

Chinitz, J. G., \& Brown, R. A. (2001). Religious homogamy, marital conflict, and stability in same faith and interfaith Jewish marriages. Journal for the Scientific Study of Religion, 40, 723-733.

Colaner, C. W. (2008). Turning points in the co-construction of religious identity in Evangelical homes. Paper presented at the National Communication Association, San Diego, CA. 
De Cremer, D., \& Tyler, T. R. (2005). A matter of intragroup status: The importance of respect for the viability of groups. In M. Thomas-Hunt (Ed.), Status and Groups (Vol. 7, pp. 1-23). Boston, MA: Emerald Group Publishing.

Edgell, P. (2005). Religion and family in a changing society. Princeton, NJ: Princeton University Press.

Farrell, J. (2011). The young and the restless? The liberalization of young evangelicals. Journal for the Scientific Study of Religion, 50, 517-532. doi:10.1111/j.1468-5906.2011.01589.x

Flor, D. L., \& Knapp, N. F. (2001). Transmission and transaction: Predicting adolescents' internalization of parental religious values. Journal of Family Psychology, 15, 627-645. doi:10.1037//08933200.15.4.627

Gaertner, S. L., \& Dovidio, J. F. (2000). Reducing intergroup bias: The common ingroup identity model. Philadelphia, PA: Psychology Press.

Gallois, C., Ogay, T., \& Giles, H. (2005). Communication accommodation theory. In W. B. Gudykunst (Ed.), Theorizing about intercultural communication (pp. 121-148). Thousand Oaks, CA: Sage.

Giles, H., Reid, S., \& Harwood, J. (2009). The dynamics of intergroup communication. New York, NY: Peter Lang Publishing.

Gunnoe, M. L., Hetherington, E. M., \& Reiss, D. (1999). Parental religiosity, parenting style, and adolescent social responsibility. The Journal of Early Adolescence, 19, 199-214. doi:10.1177/0272431699019002004

Harwood, J. (2000). Communicative predictors of solidarity in the grandparent-grandchild relationship. Journal of Social and Personal Relationships, 17, 743-766. doi:10.1177/0265407500176003

Harwood, J. (2006). Communication as social identity. In G. J. Gregory, J. Shepherd, J. St. John, \& T. Striphas (Eds.), Communication as ... Perspectives on Theory (pp. 84-91). Thousand Oaks, CA: Sage.

Harwood, J., Soliz, J., \& Lin, M. C. (2006). Communication accommodation theory: An intergroup approach to family relationships. In D. O. Braithwaite \& L. A. Baxter (Eds.), Engaging theories in family communication: Multiple perspectives (pp. 19-34). Thousand Oaks, CA: Sage.

Hayes, A. F. (2012). An analytical primer and computational tool for observed variable mediation, moderation, and conditional process modeling. Columbus, OH: The Ohio State University.

Hayes, A. F., \& Matthes, J. (2009). Computational procedures for probing interactions in OLS and logistic regression: SPSS and SAS implementations. Behavior Research Methods, 41, 924-936. doi:10.3758/BRM.41.3.924

Hughes, P. C., \& Dickson, F. C. (2005). Communication, marital satisfaction, and religious orientation in interfaith marriages. Journal of Family Communication, 5, 25-41. doi:10.1207/s15327698jfc0501_2

Hughes, P. C., \& Dickson, F. C. (2006). Relational dynamics in interfaith marriage. In L. H. Turner \& R. West (Eds.), Family communication sourcebook (pp. 373-387). Thousand Oaks, CA: Sage.

Huston, T. L., McHale, S. M., \& Crouter, A. C. (1986). When the honeymoon's over: Changes in the marriage relationship over the first year. In R. Gilmore \& S. Duck (Eds.), The emerging field of personal relationships (pp. 109-132). Hillsdale, NJ: Lawrence Erlbaum.

Lawton, L. E., \& Bures, R. (2001). Parental divorce and the switching of religious identity. Journal for the Scientific Study of Religion, 40, 99-111. doi:10.1111/0021-8294.00041

Mikkelson, A. C., \& Hesse, C. (2009). Discussions of religion and relational messages: Differences between comfortable and uncomfortable interactions. Southern Communication Journal, 74, 40-56. doi:10.1080/10417940802449382

Muthén, L. K., \& Muthén, B. (2010). Mplus user's guide. Version 6. Los Angeles, CA: Muthén \& Muthén.

Olson, D. H. (2000). Circumplex model of marital and family systems. Journal of Family Therapy, 22, 144-166. 
Parsons, R. N., Nalbone, D. P., Killmer, J. M., \& Wetchler, J. L. (2007). Identity development, differentiation, personal authority, and degree of religiosity as predictors of interfaith marital satisfaction. The American Journal of Family Therapy, 35, 343-361. doi:10.1080/01926180600814601

Pew Forum on Religion and Public Life. (2008). U.S. religious landscape survey. Washington, DC: Pew Research Center.

Regnerus, M. D. (2003). Linked lives, faith, and behavior: Intergenerational religious influence on adolescent delinquency. Journal for the Scientific Study of Religion, 42, 189-203. doi:10.1111/14685906.00172

Regnerus, M. D., Smith, C., \& Smith, B. (2004). Social context in the development of adolescent religiosity. Applied Developmental Science, 8, 27-38. doi:10.1207/S1532480XADS0801_4

Reuben, S. C. (2007). There's an Easter egg on your Seder plate: Surviving your child's interfaith marriage. Westport, CT: Praeger.

Rittenour, C. E., \& Soliz, J. (2009). Communicative and relational dimensions of shared family identity and relational intentions in mother-in-law/daughter-in-law relationships: Developing a conceptual model for mother-in-law/ daughter-in-law research. Western Journal of Communication, 73, 67-90. doi:10.1080/10570310802636334

Soliz, J. (2007). Communicative predictors of a shared family identity: Comparison of grandchildren's perceptions of family-of-origin grandparents and step-grandparents. Journal of Family Communication, 7, 177-190. doi:10.1080/15267430701221636

Soliz, J., \& Harwood, J. (2006). Shared family identity, age salience, and intergroup contact: Investigation of the grandparent-grandchild relationship. Communication Monographs, 73, 87-107. doi:10.1080/03637750500534388

Soliz, J., \& Rittenour, C. E. (2012). Family as an intergroup arena. In H. Giles (Ed.), The Handbook of intergroup communication (pp. 331-343). New York, NY: Routledge.

Soliz, J., Thorson, A. R., \& Rittenour, C. E. (2009). Communicative correlates of satisfaction, family identity, and group salience in multiracial/ethnic families. Journal of Marriage and Family, 71, 819832. doi:10.1111/j.1741-3737. 2009.00637.x

Weber, K. D., \& Patterson, B. R. (1996). Construction and validation of a communication based emotional support scale. Communication Research Reports, 13, 68-76. doi:10.1080/08824099609362072 